\title{
Nutrition Status Surveillance System in Georgia
}

\author{
Robizon Tsiklauri' ${ }^{*}$, I Parvanta ${ }^{2}$, L Jijeishvili ${ }^{3}$ M Kherkheulidze ${ }^{4}$ and N Kazakhashvili ${ }^{5}$ \\ ${ }^{1}$ NCDC Georgia, Georgia \\ ${ }^{2}$ International Expert, Georgia \\ ${ }^{3}$ LTD “Vistamedi”, Georgia \\ ${ }^{4}$ Medical University, Georgia \\ ${ }^{5} U G$, Georgia \\ *Corresponding Author: Robizon Tsiklauri, NCDC Georgia, Georgia.
}

Received: July 17, 2019; Published: September 04, 2019

\begin{abstract}
Background: Until 2015, systematic statistical data on micronutrient deficiency was not available in Georgia, to provide developing national strategy. In the same year, the National Centre for Disease Control and Public Health of Georgia (NCDC) in collaboration with the USA CDC launched the project "Strengthening surveillance of micronutrient deficiency in Georgia".

Design and Methodology: In 2015 we did choose sentinel surveillance approach. For setting nutrition surveillance system 8 sentinel sites ( 2 sites in each region/children and pregnant health facilities) in four regions of Georgia (Tbilisi, Kakheti, Achara, and Samegrelo) were selected, using the criteria of geographical, social, ethnical, urban/rural, and religion. Also, existing information about malnutrition and dietary habits from the above mentioned regions. The project protocols was approved by the Institutional review board (IRB) at the NCDC and by the Research Review Committee and Ethical review committee of the US CDC.

Design and Methodology: In 2015 we did choose sentinel surveillance approach. For setting nutrition surveillance system 8 sentinel sites ( 2 sites in each region/children and pregnant health facilities) in four regions of Georgia (Tbilisi, Kakheti, Achara, and Samegrelo) were selected, using the criteria of geographical, social, ethnical, urban/rural, and religion. Also, existing information about malnutrition and dietary habits from the above mentioned regions. The project protocols was approved by the Institutional review board (IRB) at the NCDC and by the Research Review Committee and Ethical review committee of the US CDC.

Results: As a result of surveillance system functioning (2016-2017) we reviled that, 34\% of studied children U2 (out of 939) were anemic. Furthermore, 478 were tested for iron deficiency and $84 \%$ of them were identified as iron deficient. Hemoglobin was tested among 2,790 pregnant women and 7.4\% of them were found anemic. Additionally, 483 of 2,790 pregnant women were tested for iron and folate deficiencies. $61 \%$ were iron deficient, and $26.4 \%$ tested positive for folate deficiency. Neural tube defects (NTDs) prevalence per 1000 live births registered in sentinel sites was high 2.7 .

Conclusion: Our results show that anemia and iron deficiency are prevalent among both pregnant women and children of the specified age group in Georgia. Additionally, folate deficiency was quite common during the 1st trimester of pregnancy. Our findings will inform public health policy decision makers to take relevant decisions on required interventions, such as health education, distribution of relevant supplements, and food fortification.
\end{abstract}

Keywords: Nutrition; Surveillance System; Georgia

\section{Introduction}

Micronutrient deficiencies form an important global health issue, with malnutrition affecting key development outcomes including poor physical and mental development in children, vulnerability or exacerbation of disease, mental retardation, blindness and general losses in productivity and potential. Unlike energyprotein undernourishment, the health impacts of micronutrient deficiency are not always acutely visible; it is therefore sometimes termed 'hidden hunger' (the two terms can be used interchange- ably). The World Health Organization (WHO) estimate that more than 2 billion people suffer from micronutrient deficiency globally.

Epidemiological studies for assessing the micronutrient status among the population in the South Caucasus region which includes Georgia, Azerbaijan, and Armenia, are limited. Reports from Armenia (2000) estimated the prevalence of anemia to be $12 \%$ and $12.4 \%$ among pregnant women and non-pregnant women, respectively and to be $23.9 \%$ in children under five. 
A nationwide survey (2009) in Georgia reported prevalence of $22.8 \%$ anemic children, $25.6 \%$ in pregnant and $36.6 \%$ in nonpregnant women.

Iron is an essential element for the biosynthesis of blood hemoglobin. The symptoms of iron deficiency anemia can be mild at first and are not diagnosed until they have a routine blood test. Potential health complications of iron deficiency anemia include rapid or irregular heartbeat, pregnancy complications of premature birth or low birth weight, and delayed growth in infants and children [4].

Folate insufficiency manifests in neural tube defects (NTDs), which is caused by low concentration of vitamin B9 (folate) in blood. Approximately 190,000 neonates are born with NTD in low Income Countries. TDs are serious and most common consequence of folic acid deficiencies. NTDs occur when neural tube closure is completed by embryonic day 28 of pregnancy and arise when the neural tube cannot close properly. The most common NTDs are the following: anencephaly and spina bifida [1-5].

\section{Potential target groups and study design}

Potential target groups for surveillance of micronutrient deficiency are infants, toddlers, preschool children, school-age children, and women of childbearing age. Toddlers are vulnerable to micronutrient deficiencies, are accessible for the assessment in child health clinics and community surveys, and are an indicator of risk in the general population. Surveillance of iron deficiency is focused on these vulnerable groups. In the present study women at the 1st trimester of pregnancy were studied. The study focused on following population groups including toddlers (aged $12-23$ months old), and pregnant. Selection of these target groups were based on level of risk or vulnerability, accessibility of the target group for assessment, and degree of representativeness, or the ability to reflect the extent of the problem in the overall population. Other criteria included the availability of normative data and the potential usefulness of the targeted population for surveillance of other micronutrient deficiencies.

\section{Objectives of the study}

Determining the prevalence of micronutrient deficiency (anemia, iron) in children; and determining the prevalence of micronutrient deficiency (anemia, iron, and folate) in pregnant women.

\section{Laboratory methods}

- After explaining the aim of the study (informal consent), a blood sample was collected from the anticubital vein in heparinized tube. Next, the sample is processed and the serum is separated from the clot.

- Hemoglobin was measured at the sentinel sites using multianalizators.
- Iron deficiency in survey participants has been measured using ferritin concentration in serum. Ferritin was tested in serum using the ELISA method.

- Folate deficiency has been measured using serum folate concentration measured on serum separated from blood. Testing was done using an ELISA method and a microbiologic test kit (DRG International Inc., USA. BIO-4886).

\section{Data analysis}

The Statistic Package for the Social Sciences (SPSS) was used for Data Analysis.

\section{Results}

The study in pregnant women showed $7.4 \%$ prevalence of anemia in 2790 pregnant enrolling in study; the percentage of iron deficiency in total (483 pregnant with Lab. study on ferritin) resulted in $61 \%$ ). And $26.4 \%$ of folate deficiency in 483 pregnant (with Lab. study on serum folate).

The study in children (12-23 months of age) showed 34\% prevalence of anemia in 939 children enrolling in study; the percentage of iron deficiency in total (478 children with Lab. study on ferritin) resulted in $84 \%$ ).

Anemia prevalence (percentage) by regions and target groups

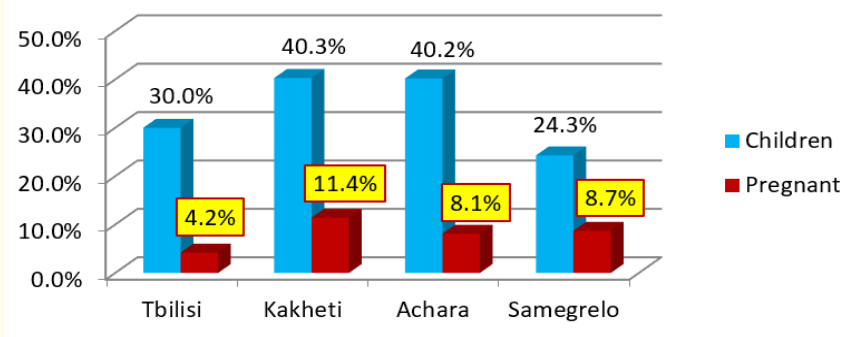

Figure 1

Severe anemia cases were not identified in both groups, not in toddlers and not in pregnant women.

In regard to regional profiles, we have detected that prevalence in toddlers in Samegrelo region (24.3\%) anemia percentage is 1.5 2 times less than in other three regions, especially when comparing with Achara (40.2\%) and Kakheti region (40.3\%). Total percentage for all four regions is $34 \%$ (Table 1).

Reviewing regional profiles for anemia and Iron deficiency in pregnant, showed that prevalence in studied 4 regions is almost the same, but with the high prevalence of Iron deficiency. And a big differences in folate deficiency between Tbilisi and Achara regions (19.2\% in Tbilisi vs 37.2\% in Achara) (Table 2). 


\begin{tabular}{|l|c|c|c|c|}
\hline \multicolumn{1}{|c|}{ Region } & \# 12-23 moths age children & Anemia Hb<110 g/L & Pregnant (1 $\mathbf{~}^{\text {st }}$ trimester) & Anemia Hb<110 g/L \\
\hline Tbilisi & 240 & All & 758 & $4.2 \%$ \\
\hline Kakheti & 336 & $30.0 \%$ & 209 & $11.4 \%$ \\
\hline Achara & 174 & $40.3 \%$ & 1606 & $8.1 \%$ \\
\hline Samegrelo & 190 & $40.2 \%$ & 217 & $8.7 \%$ \\
\hline Total & 939 & $24.3 \%$ & 2790 & $7.4 \%$ \\
\hline
\end{tabular}

Table 1: Prevalence of anemia among children and pregnant women /2016-2017 (total), by Regions.

\begin{tabular}{|l|c|c|c|c|c|}
\hline \multirow{2}{*}{ Region } & \multicolumn{2}{|c|}{ Total } & \multicolumn{2}{c|}{ Total } \\
\cline { 2 - 6 } & $\begin{array}{c}\text { \# Children } \\
(\mathbf{1 2 - 2 3} \text { moths age })\end{array}$ & Ferritin $<\mathbf{1 2 . 0} \mathbf{\mu g} / \mathbf{L}$ & $\begin{array}{c}\text { \# Pregnant } \\
\left(\mathbf{1}^{\text {st }} \text { trimester }\right)\end{array}$ & Ferritin <15.0 $\mathbf{\mu g} / \mathbf{L}$ & $\begin{array}{c}\text { Serum Folate } \\
<\mathbf{3 . 0} \mathbf{~ n g} / \mathbf{m L}\end{array}$ \\
\hline Tbilisi & 116 & $81.9 \%$ & 116 & $70.0 \%$ & $19.2 \%$ \\
\hline Kakheti & 123 & $81.3 \%$ & 120 & $54.2 \%$ & $18.3 \%$ \\
\hline Achara & 119 & $84.0 \%$ & 121 & $45.5 \%$ & $37.2 \%$ \\
\hline Samegrelo & 120 & $88.3 \%$ & 126 & $67.5 \%$ & $37.3 \%$ \\
\hline Total & 478 & $83.9 \%$ & 483 & $60.9 \%$ & $26.4 \%$ \\
\hline
\end{tabular}

Table 2: Ferritin (Iron Deficiency) 2016-2017 (total) (by Regions).

Surveillance system revealed high rate of NTDs prevalence. It's about 3 per 1000 live-birth (Table 3).
The prevalence of other forms of malnutrition (stunting, wasting, etc.) is showed in Table 4.

\begin{tabular}{|l|c|c|c|c|c|c|c|c|c|c|}
\hline Sentinels & \multicolumn{2}{|c|}{ Live-births } & \multicolumn{2}{|c|}{ Still-births } & \multicolumn{2}{c|}{$\begin{array}{c}\text { NTDs (Neural tube defects) } \\
\text { (diagnosed by ultrasound) }\end{array}$} & \multicolumn{2}{|c|}{ Abortion } & $\begin{array}{c}\text { NTDs per 1000 } \\
\text { live-birth }\end{array}$ \\
\hline & Total & With NTDs & Total & With NTDs & Total & $\begin{array}{c}\text { Spina } \\
\text { Bifida }\end{array}$ & Anencephaly & Total & With NTDs & \\
\hline Tbilisi & 3877 & 2 & 3 & 0 & 7 & 5 & 2 & 980 & 6 & \\
\hline Kakheti & 572 & 0 & 1 & 0 & 2 & 2 & 0 & 82 & 2 & \\
\hline Achara & 1073 & 0 & 1 & 0 & 5 & 4 & 1 & 564 & 5 & \\
\hline Samegrelo & 357 & 0 & 0 & 0 & 2 & 2 & 0 & 28 & 1 & \\
\hline & & & & & & & & & & \\
\hline Total & 5879 & 2 & 5 & 0 & 16 & 13 & 3 & 1654 & 14 & 2.72 \\
\hline
\end{tabular}

Table 3: NTDs prevalence 2016-2017 (total) by Regions.

\begin{tabular}{|c|c|c|c|c|c|c|c|}
\hline \# & Target group & \multicolumn{5}{|c|}{ Percentage of children with** } \\
\hline & $\begin{array}{c}\text { \# Children } \\
(\mathbf{1 2 - 2 3} \text { months })\end{array}$ & $\begin{array}{c}\text { Stunting } \\
\text { Height-for-age }\end{array}$ & \multicolumn{2}{|c|}{$\begin{array}{c}\text { Wasting } \\
\text { Weight-for-height }\end{array}$} & \multicolumn{2}{|c|}{$\begin{array}{c}\text { Underweight } \\
\text { Weight-for-age }\end{array}$} & $\begin{array}{c}\text { Overweight } \\
\text { Weight-for-height }\end{array}$ \\
\hline & & $<-2$ Z-scores* & $<-3 \mathrm{Z}$-scores & $\begin{array}{c}<-2 \mathrm{Z}- \\
\text { scores* }\end{array}$ & $\begin{array}{c}<-3 \mathrm{Z}- \\
\text { scores }\end{array}$ & $\begin{array}{c}<-2 \mathrm{Z}- \\
\text { scores* }\end{array}$ & $>+2 \mathrm{Z}$-scores \\
\hline 1 & 940 & 8.7 & 0.2 & 0.6 & 0.1 & 0.7 & 22.3 \\
\hline
\end{tabular}

Table 4: Anthropometric measurements/Prevalence of other forms of malnutrition (2016-2017).

*Category <-2 Z-scores includes <-3 Z-scores.

** Used WHO growth references. 


\section{Discussion}

This study surveyed micronutrient deficiencies of three nutrition indicators (iron, folate, and iodine) in three target groups (children of 12-23 months and 12years old children, and pregnant women in the first trimester).

According to WHO/CDC guidelines (ref), the prevalence of anemia in children population is classified as a "moderate" public health threat (by the public health significance of deficiency), but in pregnant, we have prevalence of "mild" deficiency. In terms of the folate deficiency, prevalence is high in pregnant women.

Comparing with other relevant studies, our data on anemia prevalence in children is 2.5 times higher than in Armenia but in child bearing women we have slightly lower prevalence.

Due to the project design, we could not define reasons of deficiency which require further investigation to determine proper intervention strategy.

Due to similar studies in similar context, we can assume that above mentioned deficiencies are caused due to possible reasons: a) Georgian foods do not contain sufficient amount of micronutrients. c) "Formula" for toddlers' nutrition does not contain the needed micronutrients that should meet physiological requirements of children after breastfeeding.

\section{Conclusion}

After reviewing of preliminary analyses of the sentinel approach surveillance system's 2 years (2016-2017 yy) functioning results we can conclude that: we have anemia problem in children U2; Folate deficiency problem in pregnant; Iron deficiency problem, that is reflection of the general situation existing in Georgia. According to experts opinion it is the quite sufficient evidences for final conclusion and recommendations for the initiation of nutrition interventions (mainly, food fortification) and for making the adequate changes/amendments in relative legislation. Exception of provision of Children (6-23 months) from social unprotected families with Multimicronutrients powder.

\section{Recommendations}

- $\quad$ Need to advocate for nutrition interventions regarding food fortification (with iron and folic acid) strategy.

- $\quad$ Should implement one additional project for studying the dietary habits of population using standard questionnaires.

- $\quad$ Promote the main principle of healthy eating.

- In toddlers, special nutrition powder can be used to supplement feeding menus.

\section{Acknowledgements}

This research study was funded by the United States Centres for Disease Control and Prevention (Strengthening micronutrients deficiency surveillance in Georgia- grant \# 5U2GGH001658). The re- search team/NCDC acknowledges with gratitude the commitment of the Centres for Disease Control and Prevention to the research efforts, Deputy NCDC General Director (P. Imnadze), and General Director of NCDC Georgia (A. Gamkrelidze). Also, Staff of sentinel sites (Health Facilities) and Laboratories involved in the project.

The main findings of the previous 2 years (2016-2017) project Anemia

\begin{tabular}{|c|c|c|c|}
\hline$\#$ & Contingent & $\begin{array}{c}\text { Proportion of anemia } \\
\text { in studded contingent }\end{array}$ & $\begin{array}{c}\text { Status/ } \\
\text { classification }\end{array}$ \\
\hline 1 & $\begin{array}{c}\text { Children }(12-23 \\
\text { months of age) }\end{array}$ & $34 \%$ & - \\
\hline 2 & Pregnant & $7.4 \%$ & - \\
\hline
\end{tabular}

Table 5

Iron

\begin{tabular}{|c|c|c|c|}
\hline$\#$ & Contingent & $\begin{array}{c}\text { Proportion of Iron } \\
\text { deficiency in studded } \\
\text { contingent }\end{array}$ & Status \\
\hline 1 & $\begin{array}{c}\text { Children (12-23 } \\
\text { months of age) }\end{array}$ & High (84\%) & $\begin{array}{c}\text { Iron } \\
\text { deficiency }\end{array}$ \\
\hline 2 & Pregnant & High (61\%) & $\begin{array}{c}\text { Iron } \\
\text { deficiency }\end{array}$ \\
\hline
\end{tabular}

Table 6

Iron

\begin{tabular}{|c|c|c|c|}
\hline \# & Contingent & $\begin{array}{c}\text { Proportion of folate } \\
\text { deficiency in studded } \\
\text { contingent }\end{array}$ & Status \\
\hline 1 & Pregnant & High $(26.4 \%)$ & Folate deficiency \\
\hline
\end{tabular}

Table 7

\section{Bibliography}

1. The Epidemiology of Global Micronutrient Deficiencies/Bailey R.L.a, b. West Jr. K.P.b. Black R.E.b/2015

2. Armenia Demographic and Health Survey, 2000/country profile.

3. GNS -2009/report book.

4. Iron Deficiency Anaemia Assessment, Prevention and Control/A guide for programme managers.

5. de Benoist B. "Conclusions of a WHO Technical Consultation on folate and vitamin B12 deficiencies/Food and Nutrition Bulletin". Food and Nutrition Bulletin 29.2 (2008).

Volume 3 Issue 10 October 2019

(C) All rights are reserved by Robizon Tsiklauri., et al. 